\title{
BMJ Open Stress, development and mental health study, the follow-up study of Finnish TAM cohort from adolescence to midlife: cohort profile
}

\author{
Noora Berg (D) ,,2 Olli Kiviruusu (D) , Jenna Grundström (D) , , Taina Huurre, ${ }^{1,4}$ \\ Mauri Marttunen (1) ${ }^{1,5}$
}

To cite: Berg N, Kiviruusu 0, Grundström J, et al. Stress, development and mental health study, the follow-up study of Finnish TAM cohort from adolescence to midlife: cohort profile. BMJ Open 2021;11:e046654. doi:10.1136/ bmjopen-2020-046654

- Prepublication history for this paper is available online. To view these files, please visit the journal online (http://dx.doi. org/10.1136/bmjopen-2020046654).

Received 05 November 2020 Accepted 03 November 2021

\section{Check for updates}

(c) Author(s) (or their employer(s)) 2021. Re-use permitted under CC BY-NC. No commercial re-use. See rights and permissions. Published by BMJ.

${ }^{1}$ Department of Public Health and Welfare, Finnish Institute for Health and Welfare, Helsinki, Finland

${ }^{2}$ Department of Public Health and Caring Sciences, Uppsala University, Uppsala, Sweden ${ }^{3}$ Faculty of Social Sciences, University of Helsinki, Helsinki, Finland

${ }^{4}$ Department of Education and Learning, City of Vantaa, Vantaa, Finland

${ }^{5}$ Adolescent Psychiatry, Helsinki University and Helsinki University Hospital, Helsinki, Finland

Correspondence to

Noora Berg; noora.berg@thl.fi

\section{ABSTRACT}

Purpose This cohort profile describes the Stress, development and mental health study (TAM), which is a cohort study investigating risk and protective factors as well as longitudinal associations regarding mental health and well-being from adolescence to midlife. This interdisciplinary cohort study operates, for example, in the fields of public health, social medicine, psychiatry and the life course perspective.

Participants $\ln 1981(\mathrm{n}=2242,98.0 \%$ of the target population), $1982(\mathrm{n}=2191,95.6 \%)$ and $1983(\mathrm{n}=2194$, $96.7 \%$ ) during school classes, surveys were conducted to all Finnish-speaking pupils (mostly born 1967) in the Tampere region in Finland. Participants of the school study at age 16 in $1983(n=2194)$ comprised the base population for the longitudinal data and were followedup using postal questionnaires in the years 1989, 1999 , 2009 and 2019 at ages $22(n=1656,75.5 \%$ of the age 16 participants), 32 ( $n=1471,67.0 \%), 42$ ( $n=1334,60.8 \%)$ and $52(n=1160,52.9 \%)$.

Findings to date The self-reported questionnaires include information on physical and mental health (eg, depression and mood disorders, anxiety disorders), health behaviour and substance misuse (eg, alcohol, tobacco and exercise), socioeconomic conditions, psychosocial resources (eg, self-esteem), social relationships and support, life events, etc. The numerous studies published to date have examined mental health and various factors from several perspectives such as risk and protective factors, individual developmental paths (eg, trajectories) and pathway models (mediation and moderation).

Future plans Current and future research areas include, for example, longitudinal associations between mental health (eg, depressive symptoms, self-esteem) and (1) substance use (alcohol and tobacco), (2) family transitions (eg, parenthood, relationship status) and (3) retirement. Next follow-up is planned to be conducted at the latest at age 62 in 2029. Before that it is possible to link the data with cause-of-death register.

\section{INTRODUCTION}

The Stress, development and mental health (TAM) cohort was set up to investigate how people experiencing stress and difficulties, could be supported in their development and
Strengths and limitations of this study

- This cohort covers almost completely one age cohort of one city at baseline and has a long follow-up time covering several life phases from adolescence to midlife in a 36-year follow-up.

- These data have been collected using a holistic perspective and it includes information on physical and mental health, health behaviours, socioeconomic conditions, psychosocial resources, social relationships and support, life events, etc.

- The response rates at follow-ups (52.9\%-75.5\%) are reasonably good compared with postal surveys in general and $89 \%$ of the participants have participated in at least one follow-up.

- The limitations of the cohort include rather long gaps between the follow-ups (6-10 years) and the data confining nearly only to self-reported measures.

how to prevent problems in health and wellbeing. ${ }^{1}$ Originally, the cohort study was based on concepts and theories on developmental psychopathology, stress, psychosomatic symptoms and morbidity in the framework of child and adolescent psychiatry and social medicine. In public health research, subjective health had increased interest and this study was built along with this interest. The original study questions in the 1980s dealt with the associations between stress, development and psychosomatic symptoms in adolescence and were examined by the project's longstanding principal investigator professor Hillevi Aro in her PhD project. ${ }^{2}$ Not many previous studies on stress and development had focused on adolescents and this study was set up to add knowledge on this developmentally important age phase. Already from the beginning, the aim has been to examine development from a holistic perspective covering several different dimensions of life (eg, health, health behaviour, socioeconomic 
factors, social relationships, psychosocial resources and life events). Some other Nordic longitudinal cohort studies with similar or longer follow-up time have been conducted,,$^{3-5}$ but in these studies, the starting point has not been mental health perspective. TAM cohort study is particularly focused on mental health (broadly defined) and on the role of risk and protective factors in the development of mental health during the life course, and the data are based on a whole age cohort of one region.

After the 1980s, the focus of the study has been broadened to include a life course perspective. Interest has been on both risk and protective factors ${ }^{6}$ and their interplay through the life course and associations with health and especially mental health. Risk and protective factors have included, for example, socioeconomic position (SEP), parental divorce, chronic diseases, psychosomatic symptoms, psychosocial resources and alcohol use. The current and future research areas include various perspectives associated with mental health and its development, for example, substance use (alcohol and tobacco), family transitions (eg, parenthood, relationship status) and retirement. Possibilities to link the survey data with national registers (eg, tax registers, health services) as well as conducting a substudy targeting participants children is at discretion. The project was started at the Department of Public Health in the University of Tampere and later phases have been carried out at the Finnish Institute for Health and Welfare, THL (formerly National Public Health Institute), in Finland.

\section{COHORT DESCRIPTION}

The origins of this follow-up study are three school surveys studying psychosomatic symptoms and health behaviour among adolescents that were conducted in 1981-1983 at the Department of Public Health in the University of Tampere (table 1). In these school surveys, the target population included all Finnish speaking eighth (Autumn 1981 and Spring 1982) and ninth (Spring 1983) grade pupils (mainly in 1967 born cohort) attending comprehensive schools in Tampere, an industrial and university city in Southern Finland, with some 166000 inhabitants at that time. In the 1980s, nearly all Tampere residents were Caucasian and Finnish-speaking (one Swedish-speaking school class was excluded from the cohort). Most people in Finland attend public schools, and very few private schools exist. Educational level among Tampere residents resembled levels in other cities in Finland. ${ }^{7}$ The target population was 2287 adolescents in 1981, 2291 in 1982 and 2269 in 1983. The participants of the 1983 survey $(\mathrm{n}=2194,96.7 \%)$ formed the base population for the follow-up studies (mean age 15.9, SD 0.3) (table 1).

\section{Follow-up information}

After the school survey at age 16, the cohort has been followed-up four times using postal questionnaires in 1989 at age $22(\mathrm{n}=1656,75.5 \%)$, in 1999 at age $32(\mathrm{n}=1471$, $67.0 \%)$, in 2009 at age $42(1334,60.8 \%)$ and in 2019 at age $52(n=1160,52.9 \%)$ (table 1$)$. In the first follow-up

Table 1 Target population and response rates in three school surveys and in four follow-ups

\begin{tabular}{|c|c|c|c|c|c|c|c|c|}
\hline Survey & Time & Age & $\begin{array}{l}\text { Target } \\
\text { population } \\
\text { (N) }\end{array}$ & $\begin{array}{l}\text { Number of } \\
\text { respondents (N) } \\
\text { Total } \\
\text { Women } \\
\text { Men }\end{array}$ & $\begin{array}{l}\text { Response } \\
\text { rate for } \\
\text { the target } \\
\text { population } \\
(\%)\end{array}$ & $\begin{array}{l}\text { Died } \\
\text { (N) }\end{array}$ & $\begin{array}{l}\text { Address } \\
\text { was } \\
\text { available } \\
\text { (N) }\end{array}$ & $\begin{array}{l}\text { Response } \\
\text { rate for the } \\
\text { contacted } \\
\text { population } \\
(\%)\end{array}$ \\
\hline School survey I & December 1981 & 14 & 2287 & $\begin{array}{l}2242 \\
1095 \\
1147\end{array}$ & 98.0 & - & - & - \\
\hline School survey III & May 1983 & 16 & 2269 & $\begin{array}{l}2194 \\
1071 \\
1123\end{array}$ & 96.7 & - & - & - \\
\hline Follow-up II & Spring 1999 & 32 & 2194 & $\begin{array}{l}1471 \\
805 \\
666\end{array}$ & 67.0 & 22 & 2091 & 70.4 \\
\hline Follow-up III & Spring 2009 & 42 & 2194 & $\begin{array}{l}1334 \\
734 \\
600\end{array}$ & 60.8 & 45 & 2117 & 63.0 \\
\hline Follow-up IV & Spring 2019 & 52 & 2194 & $\begin{array}{l}1160 \\
648 \\
512\end{array}$ & 52.9 & 85 & 2059 & 56.3 \\
\hline
\end{tabular}


$0.2 \%$, in the second $1.0 \%$, in the third $2.1 \%$ and in the fourth $3.9 \%$ had died.

Even though the participation rates have somewhat declined, the response rates are good compared with postal surveys in general. ${ }^{89}$ Of the age 16 participants $89 \%$ has participated in at least one, $74 \%$ in at least two, $57 \%$ in at least three and $36 \%$ in all the follow-ups, while only $11 \%$ has not participated in any of the four follow-ups.

Attrition has been studied in more detail at age $32 .{ }^{10}$ The results of that analysis showed that the most important predictors of non-response were male gender and poor school performance at age 16 years. These two variables explained away the effect of all other variables at 16 and 22 years on non-response, with the exception of earlier non-response at age 22. Findings of the attrition analyses indicated further that attrition did not bias the estimation of depression prevalence at age $32 .{ }^{10}$ Gender and school performance at 16 continued to be prominent predictors of non-response considering the whole follow-up period up to age 52: while parental lower socioeconomic position and divorce, respondent's daily smoking and heavy episodic drinking at age 16 predicted significantly lower number of responses between ages 22 and 52 (range $0-4)$, their effects were attenuated and non-significant when the effects of gender and school performance were taken into account. During the follow-ups, the participants represented well the whole age cohort in Finland, for example, in terms of marital status. ${ }^{11}$ Compared with Finnish population in general, the cohort was more educated, but in comparison to population living in cities, the educational level was similar. ${ }^{7}$

\section{Measures}

A summary of the measures in the questionnaires is presented in table 2. Questionnaires are available in English on the cohort's webpages. ${ }^{12}$ All measures are self-reported, apart from information on deaths. Data on the deaths of the study participants were provided by Statistics Finland and are linked to the data from the questionnaires using a unique personal identity number. Information on causes of deaths was classified based on the WHO's International Classification of Diseases and Related Health Problems (ICD). In the years 1983-1986 ICD- $8{ }^{13}$ was used, in the years $1987-1995$ ICD- $9{ }^{14}$ was used and from 1996 ICD-10. ${ }^{15}$ Changes in the classification system have not changed their comparability.

\section{Characteristics of the participants}

The age 52 follow-up characteristics of the TAM cohort are shown in table 3. Majority of the women $(61 \%)$ had completed high school and $70 \%$ had polytechnic level or higher education, while for the men, the respective figures were $49 \%$ and $59 \%$. Most participants were working full-time, were married or cohabiting and had children. Most participants (70\%) perceived their health good, but one fifth reported depressive symptoms. About $13 \%$ smoked daily and a fifth of women and a third of men drank alcohol at least two times a week.

\section{Patient and public involvement}

Study participants were not involved in the design, conduct or reporting of the study.

\section{FINDINGS TO DATE}

An updated list of publications can be found in the cohort's web pages. ${ }^{16}$

In this project, main interests have been on examining the role of SEP, parental divorce, chronic diseases, psychosomatic symptoms, psychosocial resources and alcohol use on subsequent well-being. Gender differences have been examined in most of the studies. Main findings from some of these domains are reviewed shortly in the following.

\section{Socioeconomic differences}

Huurre $e t a l^{17}$ examined the direction of association between psychosomatic symptoms and SEP at ages 16 , 22 and 32 and found support for both social causation (SEP predicts symptoms) and health selection (symptoms predict SEP) in women, and more for the health selection in men. Lower parental SEP in adolescence was associated with smoking in early adulthood in both genders, not having a physical leisure time activity in early adulthood in males and lower self-esteem and higher BMI at ages 22 and 32 in females after controlling for the person's own SEP. ${ }^{18}$ The strongest determinants for a person's educational level at age 32 were school achievement and parental SEP at age 16. In addition, in women, poor self-perceived health, spending less leisure time in hobbies and more on dating and in men, poor relationships with teachers and heavy drinking in adolescence, predicted lower adult educational level at age $32 .{ }^{19}$ Regarding SEP, social support and depression, we found that low SEP was associated with low social support from adolescence to adulthood, especially in women. In addition, we found some indications that low level of social support had a greater impact on depression among the lower SEP groups, but this association varied depending on the type of social support, life phase and gender. Social support did not significantly explain SEP differences in depression. ${ }^{20}$

\section{Psychosocial resources}

Another important theme in this project has been psychosocial resources and protective factors. For example, good relationships with parents, high self-esteem in adolescence and an intimate relationship protect from subsequent depression in young adulthood. ${ }^{21} 22$

\section{Self-esteem}

Results of this study project have also, using latent growth curve models, shown that self-esteem grew linearly between ages 16 and 32, but stopped thereafter. Men had a higher self-esteem throughout the follow-up, but the growth rate was faster in women. Good school achievement at age 16 was associated with higher self-esteem and parental 
Table 2 Summary of the main measures collected on the Stress, development and mental health (TAM) study in seven study phases $(1981,1982,1983,1989,1999,2009$ and 2019)

\begin{tabular}{|c|c|c|c|c|c|c|c|}
\hline \multirow[b]{2}{*}{ Measures } & \multicolumn{7}{|c|}{ Data collected } \\
\hline & 1981 & 1982 & 1983 & 1989 & 1999 & 2009 & 2019 \\
\hline \multicolumn{8}{|l|}{ Childhood family factors } \\
\hline Parental SEP, education, employment status & $x$ & & $\mathrm{x}$ & & & & \\
\hline Parental divorce, death & & & $x$ & $x$ & $x$ & $x$ & $x$ \\
\hline Family adversities (before age 16) & & & & & & $\mathrm{x}$ & \\
\hline Siblings & $x$ & & & & & & \\
\hline
\end{tabular}

Health

\begin{tabular}{|c|c|c|c|c|c|c|c|}
\hline Self-perceived health & $x$ & $x$ & $x$ & $\mathrm{x}$ & $x$ & $x$ & $x$ \\
\hline Chronic illness (list of most common + other) & $\mathrm{x}$ & & $\mathrm{x}$ & $\mathrm{x}$ & $\mathrm{x}$ & $\mathrm{x}$ & $\mathrm{x}$ \\
\hline Psychosomatic symptoms ${ }^{36}$ & $x$ & $x$ & $x$ & $x$ & $x$ & $x$ & $x$ \\
\hline Depressive symptoms (R-BDI ${ }^{37-39}$ ) & & & & $x$ & $x$ & $x$ & $x$ \\
\hline Mental health $\left(\mathrm{GHQ}-12^{40}\right)$ & & & & & $x$ & $x$ & $x$ \\
\hline Psychological distress $\left(\mathrm{K} 10^{41}\right)$ & & & & & & $x$ & $\mathrm{x}$ \\
\hline Headache/migraine & & & & $\mathrm{x}$ & $x$ & $x$ & \\
\hline Learning, memory, memory problems & & & & & & $x$ & $\mathrm{x}$ \\
\hline Use and need of mental health services & & & & & & $x$ & $x$ \\
\hline Ability to work until old age pension & & & & & & & $x$ \\
\hline Height/weight & $x$ & $\mathrm{x}$ & $x$ & $x$ & $x$ & $x$ & $\mathrm{x}$ \\
\hline Menstruation & $x$ & $x$ & $x$ & $x$ & & & \\
\hline Menopause & & & & & & & $\mathrm{x}$ \\
\hline
\end{tabular}

Health behaviour

\begin{tabular}{|c|c|c|c|c|c|c|}
\hline Frequency of alcohol use and heavy episodic drinking & $\mathrm{x}$ & $\mathrm{x}$ & $\mathrm{x}$ & $\mathrm{x}$ & $\mathrm{x}$ & $\mathrm{x}$ \\
\hline Alcohol use/alcohol disorder (AUDIT ${ }^{42}$ ) & & & & $x$ & $x$ & $\mathrm{x}$ \\
\hline Smoking & $\mathrm{x}$ & $x$ & $x$ & $x$ & $x$ & $\mathrm{x}$ \\
\hline Gambling & & & & & $x$ & $\mathrm{X}$ \\
\hline Eating behaviours & & & & & $\mathrm{x}$ & $\mathrm{x}$ \\
\hline Leisure time physical activity & $\mathrm{x}$ & & & & $\mathrm{x}$ & $\mathrm{x}$ \\
\hline Sleep duration, optimum sleep, chronotype & & & & & $\mathrm{x}$ & $\mathrm{x}$ \\
\hline
\end{tabular}

Social relationships

\section{Home atmosphere}

Relationship with mother/father

School class atmosphere, relationship with teacher and

$\begin{array}{lllll}X & & & & \\ X & X & X & X\end{array}$
classmates

Marital status

Dating

Having children

Quality of an intimate relationship

Someone to tell about difficulties/perceived availability of social

\begin{tabular}{|c|c|c|c|c|}
\hline & $X$ & $X$ & $X$ & $X$ \\
\hline \multirow[t]{3}{*}{$X$} & $X$ & $x$ & $X$ & $x$ \\
\hline & $X$ & $X$ & $X$ & $x$ \\
\hline & $X$ & $X$ & $X$ & $x$ \\
\hline$X$ & $X$ & $x$ & $X$ & $x$ \\
\hline
\end{tabular}
support

Availability and satisfaction with social support

Size of social network

\begin{tabular}{|c|c|c|}
\hline & $\mathrm{X}$ & $>$ \\
\hline$x \quad x$ & $\mathrm{x}$ & $\gamma$ \\
\hline
\end{tabular}

Education, occupation, employment

School achievement

Educational plans after ninth grade Basic education, occupational education

$\begin{array}{ll}x & x \\ x & x\end{array}$

Basic education, occupational education

$\begin{array}{llll}x & x & x & x\end{array}$


Table 2 Continued

\begin{tabular}{|c|c|c|c|c|c|c|c|}
\hline \multirow[b]{2}{*}{ Measures } & \multicolumn{7}{|c|}{ Data collected } \\
\hline & 1981 & 1982 & 1983 & 1989 & 1999 & 2009 & 2019 \\
\hline Current occupation, employment status & & & & $\mathrm{x}$ & $\mathrm{X}$ & $x$ & $x$ \\
\hline Unemployment (duration, past 10 years) & & & & & $\mathrm{x}$ & $\mathrm{X}$ & $\mathrm{X}$ \\
\hline Spouse's occupation and employment status & & & & & $\mathrm{x}$ & $x$ & $x$ \\
\hline \multicolumn{8}{|l|}{ Economic situation } \\
\hline $\begin{array}{l}\text { Perceived household subsistence, covering expenses with } \\
\text { income, household income }\end{array}$ & & & & & & $\mathrm{x}$ & $x$ \\
\hline Housing & & & & & & $\mathrm{x}$ & $\mathrm{X}$ \\
\hline Income support (past 12 months) & & & & & & & $x$ \\
\hline \multicolumn{8}{|l|}{ Psychosocial resources } \\
\hline Locus of control & & & & $\mathrm{x}$ & $\mathrm{x}$ & $\mathrm{x}$ & $x$ \\
\hline Social anxiety/sociability & & & & & $\mathrm{x}$ & $x$ & $x$ \\
\hline Self-esteem & & & $x$ & $\mathrm{x}$ & $\mathrm{x}$ & $x$ & $x$ \\
\hline Optimism & & & & & & $x$ & $x$ \\
\hline Meaningfulness & & & $\mathrm{x}$ & $\mathrm{x}$ & $\mathrm{x}$ & $x$ & $x$ \\
\hline Self-image & & & $x$ & & & & \\
\hline Satisfaction with different dimensions of life & & & & $\mathrm{x}$ & $\mathrm{x}$ & $x$ & $x$ \\
\hline Coping styles & & & & $\mathrm{x}$ & $\mathrm{x}$ & $x$ & $x$ \\
\hline \multicolumn{8}{|l|}{ Other } \\
\hline Living arrangements & $\mathrm{X}$ & $\mathrm{X}$ & & $\mathrm{x}$ & $x$ & $x$ & $\mathrm{X}$ \\
\hline Hobbies & & & $\mathrm{x}$ & $\mathrm{x}$ & & $x$ & $x$ \\
\hline TV usage & & & $\mathrm{x}$ & & & & \\
\hline Excessive internet use & & & & & & & $x$ \\
\hline Life events (within past year) & & & $\mathrm{x}$ & $\mathrm{x}$ & $\mathrm{x}$ & $x$ & $x$ \\
\hline Helping others (eg, parents) & & & & & & & $x$ \\
\hline Worries & & & $x$ & & & & \\
\hline Imagine life after 5 years from now & & & & $x$ & & & \\
\hline Hopes for future & & & $\mathrm{x}$ & $\mathrm{x}$ & & $\mathrm{x}$ & $\mathrm{x}$ \\
\hline
\end{tabular}

AUDIT, Alcohol Use Disorders Identification Test; BDI, Beck Depression Inventory; GHQ, General Health Questionnaire; K10, Kessler Psychological Distress Scale; SEP, socioeconomic position.

divorce among girls and daily smoking among boys were associated with lower self-esteem in adolescence. Daily smoking in adolescence predicted also slower growth in self-esteem among men from adolescence to midlife. ${ }^{23}$ In women, higher and increasing BMI was associated with lower and more slowly increasing self-esteem between ages 16 and 42 and these associations got stronger with age. ${ }^{24}$ In addition, those who had an increasing number of interpersonal conflicts from adolescence to midlife also had the slowest development of self-esteem. ${ }^{25}$

Parental divorce and family relationships

Those who had experienced parental divorce before the age of 16 had more often in adulthood lower education, more detrimental health behaviours, experienced more negative life events and were more often unemployed and divorced than those whose parents had not separated. Women who had experienced parental divorce had also more often psychological problems and difficulties in relationships at age $32 .{ }^{26}$ In addition, parental divorce and poor home atmosphere in adolescence predicted episodic and persistent depression in adulthood. ${ }^{27} 28$ Parental divorce was also associated with poorer quality of a person's own intimate relationship at age 32 in women. Psychosocial resources such as mother-daughter relationship, social support and self-esteem partially mediated the association between parental divorce and quality of intimate relationship. ${ }^{29}$ By analysing mediation in path analysis, we also found that poor family relationships in adolescence were part of chains of risks all the way to midlife. The pathways from poor family relationships to midlife economic adversity were shaped by low education and poor mental health in adulthood. ${ }^{30}$ The pathways from adolescence to poor midlife mental health were mainly shaped by mental health in early adulthood. ${ }^{31}$ 
Table 3 Participant characteristics at age 52 follow-up in 2019

Characteristic

Age (mean, SD)

Basic education, completed high school

\begin{tabular}{|c|c|c|c|c|c|c|}
\hline Yes (12 years) & 392 & 60.7 & 250 & 49.0 & 642 & 55.5 \\
\hline No (9 years) & 254 & 39.3 & 260 & 51.0 & 514 & 44.5 \\
\hline \multicolumn{7}{|l|}{ Highest level of education } \\
\hline University level & 152 & 23.6 & 123 & 24.2 & 275 & 23.9 \\
\hline Polytechnic or equivalent institution & 299 & 46.4 & 177 & 34.8 & 476 & 41.3 \\
\hline Vocational school or less & 194 & 30.1 & 208 & 40.9 & 402 & 34.9 \\
\hline \multicolumn{7}{|l|}{ Employment status } \\
\hline Working full-time & 511 & 79.0 & 431 & 84.7 & 942 & 81.5 \\
\hline Working part-time & 50 & 7.7 & 13 & 2.6 & 63 & 5.4 \\
\hline Unemployed & 42 & 6.5 & 26 & 5.1 & 68 & 5.9 \\
\hline Disability pension, retired or long-term sick leave & 27 & 4.2 & 31 & 6.1 & 58 & 5.0 \\
\hline Other & 17 & 2.6 & 8 & 1.6 & 25 & 2.2 \\
\hline \multicolumn{7}{|l|}{ Household income (EUR) } \\
\hline 0-1999 & 91 & 14.2 & 62 & 12.2 & 153 & 13.4 \\
\hline 2000-3999 & 232 & 36.3 & 153 & 30.2 & 385 & 33.6 \\
\hline $4000-6999$ & 257 & 40.2 & 223 & 44.0 & 480 & 41.9 \\
\hline $7000-$ & 59 & 9.2 & 69 & 13.6 & 128 & 11.2 \\
\hline \multicolumn{7}{|l|}{ Housing } \\
\hline Owner-occupied flat/house & 513 & 79.3 & 413 & 81.3 & 926 & 80.2 \\
\hline Right of residence apartments or part-ownership dwelling & 20 & 3.1 & 13 & 2.6 & 33 & 2.9 \\
\hline Rented flat & 110 & 17.0 & 79 & 15.6 & 189 & 16.4 \\
\hline Other & 4 & 0.6 & 3 & 0.6 & 7 & 0.6 \\
\hline \multicolumn{7}{|l|}{ Marital status } \\
\hline Unmarried & 76 & 11.7 & 69 & 13.5 & 145 & 12.5 \\
\hline Married & 387 & 59.7 & 316 & 61.7 & 703 & 60.6 \\
\hline Cohabiting & 93 & 14.4 & 84 & 16.4 & 177 & 15.3 \\
\hline Divorced or separated & 82 & 12.7 & 42 & 8.2 & 124 & 10.7 \\
\hline Widowed & 10 & 1.5 & 1 & 0.2 & 11 & 0.9 \\
\hline \multicolumn{7}{|l|}{ Having children } \\
\hline 0 & 121 & 19.1 & 100 & 19.8 & 221 & 19.4 \\
\hline 1 & 86 & 13.6 & 77 & 15.3 & 163 & 14.3 \\
\hline 2 & 233 & 36.8 & 167 & 33.1 & 400 & 35.1 \\
\hline 3 or more & 194 & 30.6 & 160 & 31.7 & 354 & 31.1 \\
\hline Good self-perceived health $\dagger$ & 466 & 72.6 & 341 & 66.7 & 807 & 70.0 \\
\hline Depressed* & 146 & 22.5 & 80 & 15.7 & 226 & 19.5 \\
\hline Body mass index (mean, SD) & 27.3 & $(5.52)$ & 28.2 & $(4.75)$ & 27.7 & $(5.21)$ \\
\hline Daily smoking & 84 & 13.0 & 70 & 13.9 & 154 & 13.4 \\
\hline \multicolumn{7}{|l|}{ Alcohol use } \\
\hline 2 times/week or more often & 124 & 19.2 & 166 & 32.5 & 290 & 25.1 \\
\hline
\end{tabular}

*Short 13-item Beck Depression Inventory score $\geq 5$.

†Self-perceived health 'rather good' or 'very good'.

\section{Employment status}

Household income (EUR)

\begin{tabular}{|c|c|c|c|c|c|}
\hline \multicolumn{2}{|c|}{ Women $(n=648)$} & \multicolumn{2}{|c|}{ Men $(n=512)$} & \multicolumn{2}{|c|}{ Total $(n=1160)$} \\
\hline $\mathbf{N}$ & $\%$ & $\mathbf{N}$ & $\%$ & $\mathbf{N}$ & $\%$ \\
\hline 51.9 & $(0.33)$ & 51.9 & $(0.37)$ & 51.9 & $(0.35)$ \\
\hline
\end{tabular}




\section{Alcohol use}

This study has also examined alcohol use from various perspectives. The most important determinants for age 32 alcohol use were male gender, parental divorce (before age 16), depressive symptoms, spending a lot of leisure time with friends and frequent and heavy episodic drinking at age $16 .{ }^{32}$ Five different trajectory groups of heavy episodic drinking from adolescence to midlife were identified using latent class growth analysis. The steady high and in men also increasing heavy drinking were associated with various disadvantages in midlife. ${ }^{33}$ A study examining development of psychological symptoms and heavy drinking from adolescence to midlife combined latent class analysis and latent growth modelling and concluded that the more the drinking trajectory indicated frequent heavy drinking, the higher was the level of symptoms throughout the follow-up. Results of crosslagged autoregressive analysis support the self-medication hypothesis, suggesting that alcohol is used to ease the burden of psychological symptoms. ${ }^{34}$

In conclusion, the results of these various studies show that adolescent risk and protective factors have longlasting mental health and well-being effects into adulthood. However, these effects seldom work directly, but by intertwining with later risk and protective factors and via various life course mechanisms such as accumulation and chain of risks. ${ }^{35}$

\section{Strengths and limitations of this study}

The main strengths of this study are an almost complete coverage of one age cohort of one city at baseline and the long follow-up time covering several life phases in a 36-year follow-up. The follow-up can be continued even further. Another strength is a rather holistic perspective covering several different dimensions of life. The data can be used to address many cross-disciplinary study questions. However, if the study would be initiated now, more detailed information on the childhood and family conditions and well-being (before age 14) would likely be covered.

Although there is attrition, the follow-up rates are reasonably good compared with postal surveys in general. Nevertheless, attrition (mainly related to male gender and poor school achievement) needs to be taken into account when interpreting the findings. However, the high participation rate at baseline (practically comprising the whole target group), enables elaborate examination of attrition (see reference ${ }^{10}$ ).

All the measures (except mortality) are self-reported and thus prone to the general problems of self-reporting. For example, clinical interviews would have provided more detailed information on the diagnoses of mental disorders. In addition, when the theoretical perspectives have widened, we have included some new validated measures in the follow-ups. Thus, we do not have all the information from every study phase and there have been some changes in the measures.
Collaborators The TAM data are stored and maintained at the THL in Finland. These data are not freely available due to legal restrictions and the nature of the data. Suggestions for collaboration are welcome. The main contact persons are research manager Olli Kiviruusu, at olli.kiviruusu@thl.fi and senior researcher Noora Berg, at noora.berg@thl.fi.

Contributors NB drafted the manuscript, with contributions from OK and JG. All authors commented on the manuscript. NB, JG, TH, OK and MM participated in the acquisition and interpretation of data. MM acted as the PI for the cohort. OK was responsible for data management and analyses. All authors reviewed and approved the final version of the manuscript. NB acted as the guarantor for this work.

Funding This research project has received funding from various sources throughout the years. The main funders have been Academy of Finland, the Signe and Ane Gyllenberg Foundation and the Yrjö Jahnsson Foundation. This present work was supported by the Signe and Ane Gyllenberg Foundation, grant number (N/A), the Juho Vainio Foundation, grant number (N/A) and the Finnish Foundation for Alcohol Studies, grant number (N/A)

Competing interests None declared.

Patient and public involvement Patients and/or the public were not involved in the design, or conduct, or reporting or dissemination plans of this research.

Patient consent for publication Not required.

Ethics approval The study protocol was approved by the Ethics Committee of Tampere University Hospital and the Institutional review board (IRB) of The Finnish Institute for Health and Welfare (THL) (formerly National Public Health Institute). Participants were informed of the purposes of the study and that participation was voluntary. They were requested to indicate their consent by answering the survey questionnaire.

Provenance and peer review Not commissioned; externally peer reviewed.

Data availability statement Data are available upon reasonable request. The data cannot be placed on a public repository or given as supporting files due to legal restrictions and the nature of the data (individual level data). Although the data have been analysed as pseudonymised, the original code for linking the data with participants exists (stored separately) and has not been destroyed for follow-up purposes. Individual-level data cannot be made publicly available in case the original linkage can still be retrieved, even though the actual linking information would not be made public. Suggestions for scientific collaboration are welcome. Data requests are reviewed in the Finnish Institute for Health and Welfare for compliance with the original research purposes of the study project. Suggestions for collaboration may be sent to: Noora Berg or Olli Kiviruusu, Finnish Institute for Health and Welfare, P0 Box 30, 00271 Helsinki, Finland (contact: noora.berg@thl.fi/ olli.kiviruusu@thl.fi).

Open access This is an open access article distributed in accordance with the Creative Commons Attribution Non Commercial (CC BY-NC 4.0) license, which permits others to distribute, remix, adapt, build upon this work non-commercially, and license their derivative works on different terms, provided the original work is properly cited, appropriate credit is given, any changes made indicated, and the use is non-commercial. See: http://creativecommons.org/licenses/by-nc/4.0/.

\section{ORCID iDs}

Noora Berg http://orcid.org/0000-0002-4115-3797

Olli Kiviruusu http://orcid.org/0000-0003-4864-8378

Jenna Grundström http://orcid.org/0000-0002-9754-6936

Mauri Marttunen http://orcid.org/0000-0002-3554-0264

\section{REFERENCES}

1 Aro H. Suojaavien tekijöiden tutkimus lastenpsykiatriassa. Duodecim 1989;105:1520-2.

2 Aro H. Stress, development and psychosomatic symptoms in adolescence. Academic dissertation. Acta Universitatis Tamperensis ser $A$ 1988;242:134

3 Pulkkinen L. The Jyväskylä longitudinal study of personality and social development (JYLS). In: Pulkkinen L, Kaprio J, Rose RJ, eds. Socioemotional development and health from adolescence to adulthood. New York: Cambridge University Press, 2006: 29-55.

4 University of Oulu. Northern Finland birth cohort. University of Oulu, 1966. http://urn.fi/urn:nbn:fi:att:bc1e5408-980e-4a62-b89943bec3755243

5 Raitakari OT, Juonala M, Rönnemaa T, et al. Cohort profile: the cardiovascular risk in young Finns study. Int J Epidemiol 2008;37:1220-6. 
6 Rutter M. Psychosocial resilience and protective mechanisms. Am J Orthopsychiatry 1987;57:316-31.

7 Official Statistics of Finland (OSF). Educational structure of population [e-publication]. ISSN=2242-2919. Helsinki: Statistics Finland. Available: http://www.stat.fi/til/vkour/meta_en.html [Accessed 12 May 2021].

8 Nohr EA, Liew Z. How to investigate and adjust for selection bias in cohort studies. Acta Obstet Gynecol Scand 2018;97:407-16.

9 Galea S, Tracy M. Participation rates in epidemiologic studies. Ann Epidemiol 2007:17:643-53.

10 Eerola M, Huurre T, Aro $\mathrm{H}$. The problem of attrition in a Finnish longitudinal survey on depression. Eur J Epidemiol 2005;20:113-20.

11 Official Statistics of Finland (OSF). Population structure [epublication]. ISSN=1797-5395. Helsinki: Statistics Finland. Available: http://www.stat.fi/til/vaerak/meta en.html [Accessed 12 May 2021].

12 Questionnaires on cohort's webpage. Available: https://thl.fi/en/web/ thlfi-en/research-and-expertwork/projects-and-programmes/stressdevelopment-and-mental-health-the-tam-project-/questions-askedon-the-surveys

13 World Health Organization. Manual of the international statistical classification of disease, injuries, and causes of death. Based on the recommendations of the eighth revision conference, 1965, and adopted by the Nineteenth World Health Assembly, 1967. Available: https://apps.who.int/iris/handle/10665/70934

14 World Health Organization. World Health Organization \& International Conference for the Ninth Revision of the International Classification of Diseases (1975: Geneva). Manual of the international statistical classification of diseases, injuries, and causes of death : based on the recommendations of the ninth revision conference, 1975, and adopted by the Twenty-ninth World Health Assembly, 1975 revision. 1977. Available: https://apps.who.int/iris/handle/10665/40492

15 World Health Organization. International statistical classification of diseases and related health problems. World Health Organization, 1994. https://apps. who.int/iris/handle/10665/38450

16 List of publications on cohort's webpage. Available: https://thl.fi/en/ web/thlfi-en/research-and-expertwork/projects-and-programmes/ stress-development-and-mental-health-the-tam-project- $/$ publications

17 Huurre T, Rahkonen O, Komulainen E, et al. Socioeconomic status as a cause and consequence of psychosomatic symptoms from adolescence to adulthood. Soc Psychiatry Psychiatr Epidemiol 2005; $40: 580-7$.

18 Huurre T, Aro H, Rahkonen O. Well-being and health behaviour by parental socioeconomic status: a follow-up study of adolescents aged 16 until age 32 years. Soc Psychiatry Psychiatr Epidemiol 2003;38:249-55.

19 Huurre T, Aro H, Rahkonen O, et al. Health, lifestyle, family and school factors in adolescence: predicting adult educational level. Educ Res 2006;48:41-53

20 Huurre T, Eerola M, Rahkonen O, et al. Does social support affect the relationship between socioeconomic status and depression? A longitudinal study from adolescence to adulthood. J Affect Disord 2007;100:55-64.

21 Palosaari UK, Aro HM. Parental divorce, self-esteem and depression: an intimate relationship as a protective factor in young adulthood. $J$ Affect Disord 1995;35:91-6.

22 Palosaari U, Aro H, Laippala P. Parental divorce and depression in young adulthood: adolescents' closeness to parents and self-esteem as mediating factor. Acta Psychiatr Scand 1996;93:20-6.

23 Kiviruusu O, Huurre T, Aro $\mathrm{H}$, et al. Self-esteem growth trajectory from adolescence to mid-adulthood and its predictors in adolescence. Adv Life Course Res 2015;23:29-43.
24 Kiviruusu O, Konttinen $\mathrm{H}$, Huurre T, et al. Self-esteem and body mass index from adolescence to mid-adulthood. A 26-year follow-up. Int $J$ Behav Med 2016;23:355-63.

25 Kiviruusu O, Berg N, Huurre T, et al. Interpersonal conflicts and development of self-esteem from adolescence to mid-adulthood. A 26-year follow-up. PLoS One 2016b;11:e0164942.

26 Huurre T, Junkkari $\mathrm{H}$, Aro $\mathrm{H}$. Long-term psychosocial effects of parental divorce. A follow-up study from adolescence to adulthood. Eur Arch Psych Clin Neurosci 2006;256:256-63.

27 Pelkonen M, Marttunen M, Aro H. Risk for depression: a 6-year follow-up of Finnish adolescents. J Affect Disord 2003;77:41-51.

28 Pelkonen M, Marttunen M, Kaprio J, et al. Adolescent risk factors for episodic and persistent depression in adulthood. A 16-year prospective follow-up study of adolescents. J Affect Disord 2008;106:123-31.

29 Mustonen U, Huurre T, Kiviruusu O, et al. Long-term impact of parental divorce on intimate relationship quality in adulthood and the mediating role of psychosocial resources. J Fam Psychol 2011;25:615-9.

30 Berg N, Kiviruusu O, Karvonen S, et al. Pathways from poor family relationships in adolescence to economic adversity in midadulthood. Adv Life Course Res 2017;32:65-78.

31 Berg N, Kiviruusu O, Karvonen S, et al. Pathways from problems in adolescent family relationships to midlife mental health via early adulthood disadvantages - a 26-year longitudinal study. PLoS One 2017;12:e0178136.

32 Huurre T, Lintonen T, Kaprio J, et al. Adolescent risk factors for excessive alcohol use at age 32 years. A 16-year prospective follow-up study. Soc Psychiatry Psychiatr Epidemiol 2010;45:125-34.

33 Berg N, Kiviruusu O, Karvonen S, et al. A 26-year follow-up study of heavy drinking trajectories from adolescence to mid-adulthood and adult disadvantage. Alcohol Alcohol 2013;48:452-7.

34 Berg NJ, Kiviruusu OH, Lintonen TP, et al. Longitudinal prospective associations between psychological symptoms and heavy episodic drinking from adolescence to midlife. Scand J Public Health 2019;47:420-7.

35 Kuh D, Ben-Shlomo Y, Lynch J, et al. Life course epidemiology. J Epidemiol Community Health 2003;57:778-83.

36 Aro S. Stress, morbidity, and health-related behaviour. A five-year follow-up study among metal industry employees. Scand J Soc Med Supp/ 1981;25:1-130.

37 Beck AT, Beck RW. Screening depressed patients in family practice. A rapid technic. Postgrad Med 1972;52:81-5.

38 Kaltiala-Heino R, Rimpelä M, Rantanen P. Finnish modification of the 13-item Beck depression inventory in screening an adolescent population for depressiveness and positive mood. Nord. J. Psychiatry 1999;53:451-7.

39 Raitasalo R. Mood questionnaire. Finnish modification of the short form of the Beck depression inventory measuring depression symptoms and self-esteem. Helsinki: The Social Insurance Institution, 2007.

40 Goldberg DP. The detection of psychiatric illness by questionnaire. Maudsley monographs No. 21. London: Oxford University Press, 1972.

41 Kessler RC, Andrews G, Colpe LJ, et al. Short screening scales to monitor population prevalences and trends in non-specific psychological distress. Psychol Med 2002;32:959-76.

42 Babor TF, de la Fuente JR, Saunders JB. AUDIT - the alcohol use disorders identification test: quidelines for use in primary care. 2 nd edn. Geneva: World Health Organization, 2001. 